ఠ

\title{
Fixed combinations in the pragmatic management of hypertension: focus on aliskiren and hydrochlorothiazide as a single pill
}

This article was published in the following Dove Press journal:

Integrated Blood Pressure Control

26 May 2010

Number of times this article has been viewed

\section{Michel Burnier}

Service of Nephrology and Hypertension, University Hospital, Lausanne, Switzerland
Correspondence: $M$ Burnier

Service of Nephrology and Hypertension, CHUV, Rue du Bugnon 17, I0II Lausanne, Switzerland

$\mathrm{Tel}+4|2| 3|4||| 54$

Fax +4| 2I 3|4 I| 39

Email michel.burnier@chuv.ch
Abstract: A majority of hypertensive patients need more than one antihypertensive drug to control their blood pressure. For this reason, most guidelines have introduced the possibility of prescribing fixed-dose combination therapies as first-line treatment in hypertension. Today, the concept of fixed-dose combinations has evolved and the term single pill combination might become more appropriate to reflect the large choice of drug combinations available on the market. Recently, a new single pill combination has been launched which combines the first direct renin inhibitor aliskiren and low doses of hydrochlorothiazide. This paper reviews the potential advantages of single pill combinations and presents the first results obtained with the aliskiren/HCTZ single pill combination in hypertension.

Keywords: hypertension, drug adherence, combination therapies, diuretics, renin inhibition

\section{Introduction}

According to the most recent guidelines, the goal of hypertension management is to reduce blood pressure below $140 / 90 \mathrm{mmHg}$ and to even lower targets in patients with a high cardiovascular risk in order to decrease the incidence of cardiovascular events such as stroke, myocardial infarction, congestive heart failure, and end stage renal disease and hence cardiovascular deaths. ${ }^{1,2}$ Numerous studies have demonstrated that to reach these target blood pressures physicians need to prescribe more than one antihypertensive agent. ${ }^{3,4}$ Thus, in the Antihypertensive and Lipid-Lowering treatment to prevent Heart Attack Trial (ALLHAT) study, 63\% of the patients received 2 or more drugs to control their blood pressure. ${ }^{4}$ In the Hypertension Optimal Treatment (HOT) study, the average number of antihypertensive drugs to reach a diastolic blood pressure of $80 \mathrm{mmHg}$ or less was greater than $3,{ }^{5}$ and in the more recent ACCOMPLISH cohort, $74 \%$ of patients were receiving 2 antihypertensive agents or more at baseline, ie, before the administration of the tested combinations. ${ }^{6}$ These figures are also supported by the results of national surveys on hypertension indicating that most hypertensive patients need more than 2 antihypertensive drugs. For example, in a large unselected group of 2199 hypertensive patients managed in private practice in Switzerland, we reported recently that $50 \%$ of patients needed more than a combination therapy to achieve the desired blood pressure values. ${ }^{7}$

\section{From fixed low-dose combinations to single pill combinations}

In recent years, there has been a progressive shift from the classical step care approach to the use of combination therapies as first-line therapy. ${ }^{8}$ This change in paradigm has submit your manuscript | www.dovepress.com

Dovepress

5077 
resulted from the evidence that although a single therapy is the preferred approach to treat hypertensive patients, this strategy is at best effective in correcting blood pressure in patients with stage I or II hypertension. Pragmatically, multiple-mechanism therapies should have a greater efficacy in controlling blood pressure in hypertensive patients, and it became rapidly obvious that with the use of combinations, a greater percentage of patients could indeed be brought to target more quickly. The increased efficacy of combination therapies reflects the fact that several pathophysiological mechanisms control blood pressure and that the likelihood of normalizing blood pressure is higher if more than one blood pressure control pathway is attacked. In addition, when combining therapeutic strategies, each component has the potential to neutralize counter-regulatory mechanisms and the development of potential side-effects, and the blood pressure-lowering effect is enhanced. One good example of such a synergism is the association of a blocker of the renin-angiotensin system (RAS) and a thiazide diuretic. The thiazide-induced natriuresis potentiates the antihypertensive efficacy of the RAS blocker by stimulating renin, whereas the RAS blocker limits the kaliuresis induced by the thiazide diuretic and therefore limits the incidence of hypokalemia. ${ }^{9}$

The concept of fixed-dose combinations started initially with low-dose combination because combining 2 drugs at low dose was found to increase the antihypertensive efficacy while reducing significantly the incidence of side-effects, hence leading to an improved tolerability profile. ${ }^{10}$ But the prescription of low dose combinations was justified when antihypertensive drugs were characterized by a dose-dependent increase in side-effects. The concept was recently challenged with the introduction of angiotensin II receptor blockers (ARBs) which have a tolerability profile comparable to placebo even at higher doses. ${ }^{11}$ In this case, the use of low dose combinations is not really justified except possibly for the component of the combination with which the ARB is associated, ie, the diuretic or the calcium channel blocker. Thus the use of the generic term of "fixed low-dose combinations" could be questioned. In a recent small survey, we have investigated the implementation of combination treatments of hypertension in general practice and whether "single pill combination" would not be a better term to use than "fixed-dose combinations" (Burnier M, Neely P, unpublished poster, Am Soc Hypertens Meeting 2009; Figure 1). Indeed, single pill combination means that 2 or more drugs can be administered in a single pill whatever the dose. This formulation implies simplicity and flexibility. In contrast, the formulation fixeddose combinations implies that drugs are combined with a perception of lack of flexibility because of the term "fixed". To investigate the perception of these formulations on the

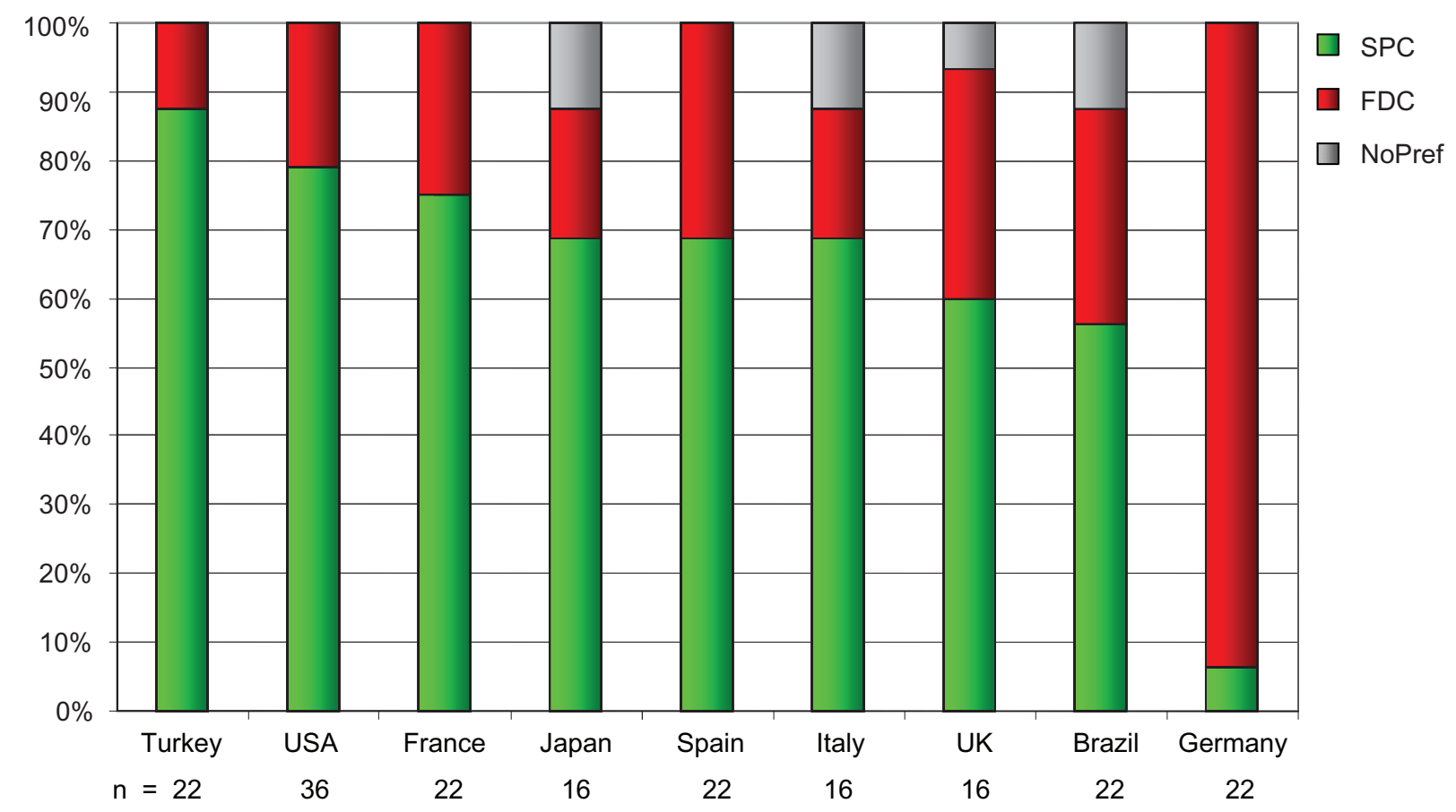

Figure I Summary of the preference for the term single pill combination (SPC) versus fixed-dose combinations (FDC) among physicians interviewed in various countries. Single pill combination expresses the practice of giving 2 or more drugs in a single pill, which means simplicity and flexibility. In contrast, fixed-dose combinations reflects the fact that 2 drugs at fixed doses are combined, implying a simplified treatment but generally less flexibility because of the term "fixed". 
field, 1-hour interviews were conducted with 76 general practitioners, 76 specialists, and 48 patients around the world. In all countries, specialists were more likely to use combinations as first-line therapy than GPs, who tend to prescribe them only as a next step on from monotherapy. In this respect, the survey confirms a certain under-use of combination therapies considering the level of blood pressure control in the population. ${ }^{12}$ Interestingly, in all countries but Germany (Figure 1), the expression single pill combination was preferred mainly by patients and specialists and was found to create a more positive perception of combination products than fixed-dose combination, which gives the impression of being limited by the fixed component of the association. Thus, single pill combination could be proposed as the generic term to promote the use of combination therapies until the availability of the polypill, which combines therapeutic principles covering different diseases or risk factors. ${ }^{13}$

\section{The other potential advantages of single pill combinations}

Poor compliance and persistence are known to be major problems in all patients with chronic diseases and even more so when the disease is silent. ${ }^{14}$ It is estimated that $29 \%$ to $58 \%$ of patients are non-persistent with therapy (persistence defined as remaining on treatment for 12 months) and $24 \%$ to $51 \%$ are non-compliant (compliance defined as drugs available $>80 \%$ of days in a year). ${ }^{15}$ In the US an estimated $14 \%$ of all prescriptions are never filled and an additional $13 \%$ are filled but never taken. ${ }^{16}$ Compliance and persistence appear to have an inverse relationship with time. A large retrospective cohort study of over 2000 new antihypertensive medication users over a 10-year period has illustrated this point and shown that the largest dropoff occurs in the first years; among patients still in therapy after the first year, 50\% stopped treatment within the next 2 years. ${ }^{17}$

One of the major reasons why single pill combinations may provide greater benefits in terms of blood pressure control is certainly linked to drug adherence. Single pill combinations are likely to increase compliance and persistence because they simplify the treatment regimen and reduce the pill burden. Data are now accumulating to substantiate this hypothesis, and in a recent meta-analysis, non-compliance to study medication was reduced by around $25 \%$ in patients receiving a single pill combination versus free drug combinations. ${ }^{18}$ In addition, with a low pill burden, patients have a different perception of their disease which may help to support their long-term adherence to therapy.
Single pill combinations are often advantageous over single agents in terms of tolerability. As discussed earlier, the occurrence of adverse effects associated with antihypertensive drugs increases with higher drug doses except for ARBs. Single pill combinations are usually associated with lower doses of the individual components, which translates into a reduced likelihood of adverse events. Again, there is a wealth of data to support this statement. In a large metaanalysis of 5 different categories of antihypertensive agents, the incidence of adverse effects with drug combinations was significantly less than additive, suggesting that antihypertensive agents given in fixed-dose combinations do not potentiate the adverse effects of one another. ${ }^{10}$

The favorable impact of single pill combination therapies on blood pressure control should contribute to reduce cardiovascular morbidity and mortality. This might in turn translate into reduced numbers of physician visits and hospital admissions, shortened hospital stays, reduced non-drug and overall healthcare expenditure, and improved productivity. Thus, a wider use of single pill combinations could potentially reduce the overall cost of treatments. ${ }^{19}$ Whether this is indeed the case has not yet been proven definitively. Today, there are large variations among countries in the way single pill combination therapies are reimbursed and several financial barriers exist in some countries that limit a wider use of these combinations.

\section{Aliskiren plus hydrochlorothiazide: a new single pill combination for hypertension}

Direct renin inhibition (DRI) is a new way to interfere with the RAS, interrupting the enzymatic cascade at its first ratelimiting step, ie, the conversion of angiotensinogen into angiotensin I by renin. In this class of agents, aliskiren is the first nonpeptide DRI which has been approved for the treatment of hypertension in the US as well as in Europe.

Aliskiren is a transition-state mimetic agent with high hydrophilicity. This characteristic improves its oral bioavailability which remains relatively low but is better than that of all earlier renin inhibitors and, in any case, sufficient to provide a sustained renin inhibition in humans. ${ }^{20}$ Aliskiren inhibits human renin with an $\mathrm{IC}_{50}$ of $0.6 \mathrm{nmol} / \mathrm{L}$, and preclinical data in salt-depleted normotensive and hypertensive animals have demonstrated that aliskiren is an effective blood pressure-lowering agent. ${ }^{21}$ Experimentally, aliskiren is as effective as other blockers of the RAS system in preventing atherosclerosis and cardiovascular and renal complications in models with an activated RAS. ${ }^{22,23}$ 
In humans, aliskiren induces a dose-dependent inhibition of the RAS system in healthy volunteers ${ }^{20}$ as well as a dose-dependent decrease in blood pressure in hypertensive patients. $^{24,25}$ Compared with other antihypertensive agents, aliskiren was found to be as effective in lowering blood pressure as an angiotensin-converting enzyme (ACE) inhibitor, an ARB, or a beta-blocker, and in some instances, depending on the pharmacological characteristics of the comparator, aliskiren provided a more sustained effect on blood pressure. ${ }^{24-27}$ This is due essentially to the particularly long duration of action of aliskiren which provides a sustained antihypertensive efficacy beyond $24 \mathrm{~h}$ thus lowering blood pressure even after a missed dose. When compared to a thiazide diuretic, aliskiren was found to provide a significantly greater reduction in blood pressure in a very large group of hypertensive patients. ${ }^{28}$

Similarly to ACE inhibitors and ARBs, aliskiren can be associated with a thiazide diuretic in order to increase its antihypertensive efficacy. As mentioned previously, the thiazide-induced salt depletion stimulates renin secretion, and hence blood pressure becomes more renin dependent. This was well demonstrated in a large study in which several doses of hydrochlorothiazide (HCTZ) and aliskiren were compared as single agents or in combinations. ${ }^{29}$ This study found a clear additive effect of the thiazide diuretic, which led to the development of single pill combinations of aliskiren and HCTZ (Figure 2). Additional randomized prospective studies have demonstrated that adding a thiazide diuretic in patients not responding to aliskiren alone or, conversely, adding aliskiren to a thiazide in non-responders to the diuretic provide significant additional blood pressure reductions. ${ }^{28,30-32}$ Thus, in obese patients who did not respond to a 4-week treatment of HCTZ, Jordan et al demonstrated that adding aliskiren could provide additional blood pressure-lowering efficacy while preserving an excellent tolerability profile. ${ }^{31}$ In this population, the addition of aliskiren to HCTZ was superior to adding a placebo to the diuretic but comparable to the addition of an ARB or a calcium channel blocker. However, the aliskiren/HCTZ combination was better tolerated than the $\mathrm{CCB} / \mathrm{HCTZ}$ combination. Aliskiren has also been studied in patients not responding to the calcium channel blocker amlodipine. In this group of patients, adding aliskiren in patients receiving $5 \mathrm{mg}$ of amlodipine was as effective as

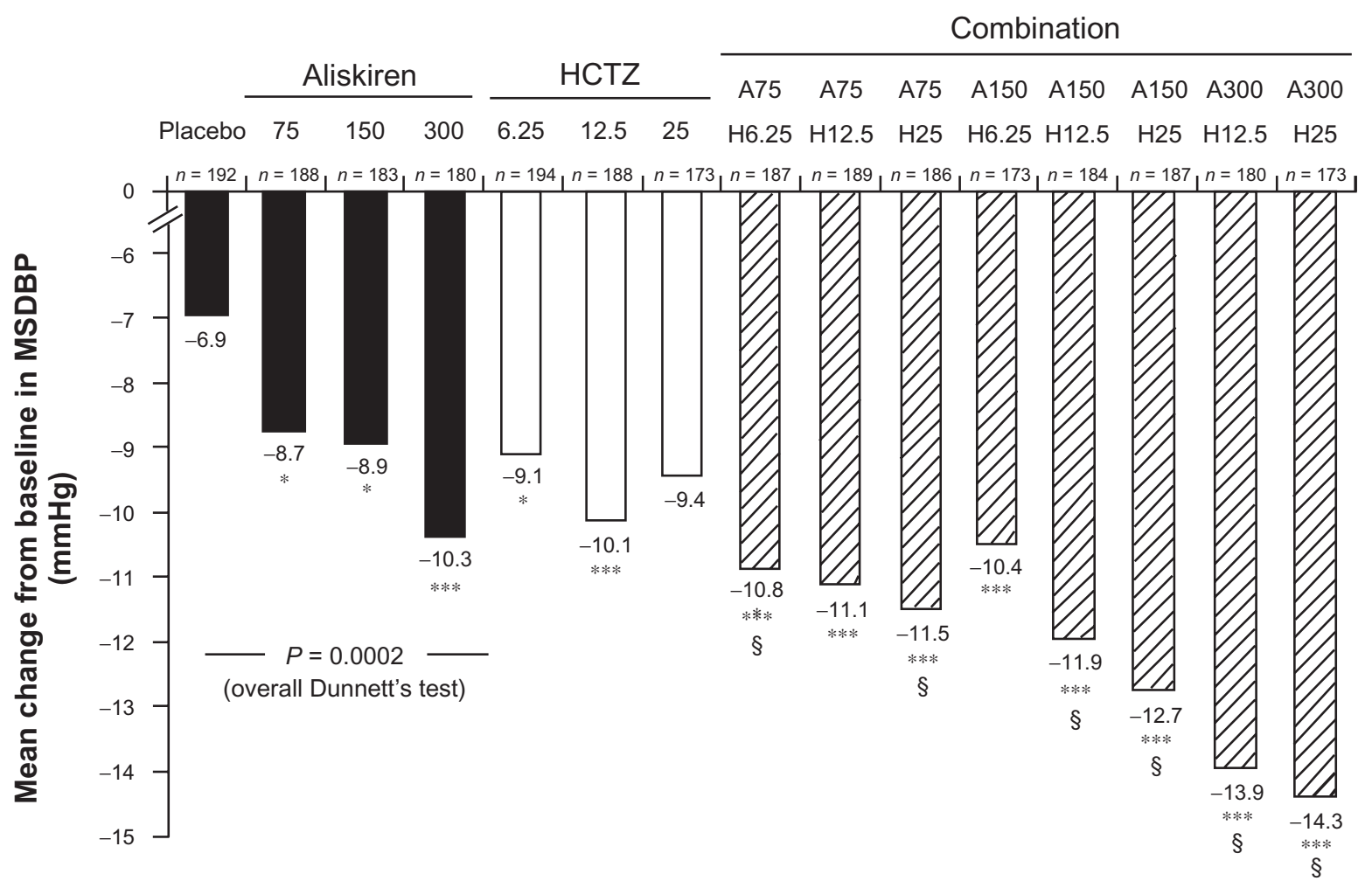

Figure 2 Changes in mean sitting diastolic blood pressure (MSDBP) induced by increasing doses of aliskiren or hydrochlorothiazide (HCTZ) administered alone or in combination to hypertensive patients. Reproduced with permission from Villamil A, Chrysant SG, Calhoun D, et al. Renin inhibition with aliskiren provides additive antihypertensive efficacy when used in combination with hydrochlorothiazide.J Hypertens. 2007;25:217-226. ${ }^{29}$ Copyright @ 2007 Wolters Kluwer Health. 
doubling the dose of amlodipine but was better tolerated as it induced less peripheral edema. ${ }^{30,33}$

\section{Aliskiren single pill combinations: which will be the right one?}

Today, aliskiren is available on many markets as single-agent therapy at doses of $150 \mathrm{mg}$ and $300 \mathrm{mg}$ as well as singlepill combinations with HCTZ $12.5 \mathrm{mg}$ and $25 \mathrm{mg}$. At these doses, aliskiren has been found to be effective and well tolerated, as summarized above. Using doses of aliskiren greater than $300 \mathrm{mg}$ would increase the risk of developing diarrhea and, therefore, higher doses are not recommended. Studies have demonstrated that aliskiren could also be combined with a calcium channel blocker or with an ARB to enhance its antihypertensive efficacy and to provide organ protection. ${ }^{27,33}$ Thus, one question will soon arise: in which patient should a single pill combination be preferred to another one? Indeed, the recent results of the ACCOMPLISH trial have suggested that combining a blocker of the RAS system with a calcium channel blocker may be a better choice than combining a RAS blocker with a diuretic in patients with a high cardiovascular risk. ${ }^{6,27}$ This may be true for the specific population enrolled in this study, ie, mainly obese patients and patients with a metabolic syndrome and a very high cardiovascular risk profile. In these patients, the prescription of a thiazide diuretic might actually increase the risk of developing diabetes. Therefore, diuretics should perhaps be prescribed as second- or third-line therapy in such patients. Nonetheless, single pill combination of a RAS blocker and a thiazide remains a very effective strategy to control blood pressure in a large proportion of the population. Thus, in a recent Canadian randomized controlled study, investigators compared a simplified algorithm for the treatment of hypertension based on the initial use of a single pill combination of a diuretic and a RAS blocker with the conventional guideline-based care recommending a step-care approach. ${ }^{34}$ The initial use of single pill combinations was associated with a significantly higher proportion of patients achieving the target blood pressure (64.7 vs 52.7\%). These results thus not only confirmed the superiority of single pill combinations over individual therapies but also confirm the usefulness of single pill combinations involving a thiazide diuretic and a RAS blocker in the management of hypertensive patients. The single pill combination of aliskiren and HCTZ is an effective alternative to the use of ACE inhibitors and ARBs associated with diuretics in hypertension. In the future, the availability of 2 single pill combinations involving aliskiren, one with HCTZ and another one with amlodipine, will provide all the possible alternatives to treat hypertensive patients.

\section{Conclusions}

Pragmatically, greater clinical use of single pill combinations could probably be very helpful in increasing the percentage of hypertensive patients with a well-controlled blood pressure. Single pill combinations have several advantages over individual therapies, the most important a reduction of the pill burden and an improvement in long-term drug adherence. The excellent tolerability profile of single pill combinations involving a RAS blocker and a thiazide diuretic is another positive aspect that should be taken into account when prescribing a new treatment. The recent development of the first direct renin inhibitor aliskiren, which is now also available as a single pill combination with HCTZ, represents a new opportunity to improve our ability to control blood pressure and to prevent target organ damage. Because of its efficacy and long-duration of action, aliskiren is an interesting alternative to ACE inhibitors and ARBs, and numerous large clinical trials are now ongoing to demonstrate its ability to provide organ protection and to reduce cardiovascular morbidity and mortality. ${ }^{35}$

\section{Disclosure}

The author discloses no conflicts of interest.

\section{References}

1. Chobanian AV, Bakris GL, Black HR, et al. Seventh report of the Joint National Committee on Prevention, Detection, Evaluation, and Treatment of High Blood Pressure. Hypertension. 2003;42:1206-1252.

2. Cifkova R, Erdine S, Fagard R, et al. Practice guidelines for primary care physicians: 2003 ESH/ESC hypertension guidelines. J Hypertens. 2003;21:1779-1786.

3. Bakris GL, Williams M, Dworkin L, et al. Preserving renal function in adults with hypertension and diabetes: a consensus approach. National Kidney Foundation Hypertension and Diabetes Executive Committees Working Group. Am J Kidney Dis. 2000;36:646-661.

4. Cushman WC, Ford CE, Cutler JA, et al. Success and predictors of blood pressure control in diverse North American settings: the antihypertensive and lipid-lowering treatment to prevent heart attack trial (ALLHAT). $J$ Clin Hypertens (Greenwich). 2002;4:393-404.

5. Hansson L, Zanchetti A, Carruthers SG, et al. Effects of intensive blood-pressure lowering and low-dose aspirin in patients with hypertension: principal results of the Hypertension Optimal Treatment (HOT) randomised trial. HOT Study Group. Lancet. 1998;351:1755-1762.

6. Jamerson K, Weber MA, Bakris GL, et al. Benazepril plus amlodipine or hydrochlorothiazide for hypertension in high-risk patients. $N$ Engl J Med. 2008;359:2417-2428.

7. Burnier M, Gasser UE. Efficacy and tolerability of lercanidipine in patients with hypertension: results of a Phase IV study in general practice. Expert Opin Pharmacother. 2007;8:2215-2223.

8. Sica DA. Rationale for fixed-dose combinations in the treatment of hypertension: the cycle repeats. Drugs. 2002;62:443-462.

9. Kochar M, Guthrie R, Triscari J, Kassler-Taub K, Reeves RA. Matrix study of irbesartan with hydrochlorothiazide in mild-to-moderate hypertension. Am J Hypertens. 1999;12:797-805. 
10. Law MR, Wald NJ, Morris JK, Jordan RE. Value of low dose combination treatment with blood pressure lowering drugs: analysis of 354 randomised trials. BMJ. 2003;326:1427.

11. Burnier M. Angiotensin II type 1 receptor blockers. Circulation. 2001;103:904-912.

12. Ferrari P, Hess L, Pechere-Bertschi A, Muggli F, Burnier M. Reasons for not intensifying antihypertensive treatment (RIAT): a primary care antihypertensive intervention study. J Hypertens. 2004;22:1221-1229.

13. Wald NJ, Law MR. A strategy to reduce cardiovascular disease by more than $80 \%$. BMJ. 2003;326:1419.

14. Vrijens B, Vincze G, Kristanto P, Urquhart J, Burnier M. Adherence to prescribed antihypertensive drug treatments: longitudinal study of electronically compiled dosing histories. BMJ. 2008;336:1114-1117.

15. Gerth WC. Compliance and persistence with newer antihypertensive agents. Curr Hypertens Rep. 2002;4:424-433.

16. Chapman RH, Benner JS, Petrilla AA, et al. Predictors of adherence with antihypertensive and lipid-lowering therapy. Arch Intern Med. 2005; $165: 1147-1152$.

17. van Wijk BL, Klungel OH, Heerdink ER, de BA. Rate and determinants of 10-year persistence with antihypertensive drugs. J Hypertens. 2005;23:2101-2107.

18. Bangalore S, Kamalakkannan G, Parkar S, Messerli FH. Fixed-dose combinations improve medication compliance: a meta-analysis. Am J Med. 2007;120:713-719.

19. Ruilope LM, Burnier M, Muszbek N, et al. Public health value of fixeddose combinations in hypertension. Blood Press Suppl. 2008;1:5-14.

20. Nussberger J, Wuerzner G, Jensen C, Brunner HR. Angiotensin II suppression in humans by the orally active renin inhibitor Aliskiren (SPP100): comparison with enalapril. Hypertension. 2002;39:E1-E8.

21. Wood JM, Schnell CR, Cumin F, Menard J, Webb RL. Aliskiren, a novel, orally effective renin inhibitor, lowers blood pressure in marmosets and spontaneously hypertensive rats. J Hypertens. 2005;23:417-426.

22. Nussberger J, Aubert JF, Bouzourene K, Pellegrin M, Hayoz D, Mazzolai L. Renin inhibition by aliskiren prevents atherosclerosis progression: comparison with irbesartan, atenolol, and amlodipine. Hypertension. 2008;51:1306-1311.

23. Pilz B, Shagdarsuren E, Wellner M, et al. Aliskiren, a human renin inhibitor, ameliorates cardiac and renal damage in double-transgenic rats. Hypertension. 2005;46:569-576.

24. Gradman AH, Schmieder RE, Lins RL, Nussberger J, Chiang Y, Bedigian MP. Aliskiren, a novel orally effective renin inhibitor, provides dose-dependent antihypertensive efficacy and placebo-like tolerability in hypertensive patients. Circulation. 2005;111:1012-1018.
25. Stanton A, Jensen C, Nussberger J, O’Brien E. Blood pressure lowering in essential hypertension with an oral renin inhibitor, aliskiren. Hypertension. 2003;42:1137-1143.

26. Dietz R, Dechend R, Yu CM, et al. Effects of the direct renin inhibitor aliskiren and atenolol alone or in combination in patients with hypertension1. J Renin Angiotensin Aldosterone Syst. 2008;9:163-175.

27. Oparil S, Yarows SA, Patel S, Fang H, Zhang J, Satlin A. Efficacy and safety of combined use of aliskiren and valsartan in patients with hypertension: a randomised, double-blind trial. Lancet. 2007;370:221-229.

28. Schmieder RE, Philipp T, Guerediaga J, et al. Long-term antihypertensive efficacy and safety of the oral direct renin inhibitor aliskiren: a 12-month randomized, double-blind comparator trial with hydrochlorothiazide. Circulation. 2009;119:417-425.

29. Villamil A, Chrysant SG, Calhoun D, et al. Renin inhibition with aliskiren provides additive antihypertensive efficacy when used in combination with hydrochlorothiazide. J Hypertens. 2007;25:217-226.

30. Andersen K, Weinberger MH, Egan B, et al. Comparative efficacy and safety of aliskiren, an oral direct renin inhibitor, and ramipril in hypertension: a 6-month, randomized, double-blind trial. J Hypertens. 2008;26:589-599.

31. Jordan J, Engeli S, Boye SW, Le BS, Keefe DL. Direct Renin inhibition with aliskiren in obese patients with arterial hypertension. Hypertension. 2007;49:1047-1055.

32. Nickenig G, Simanenkov V, Lembo G, et al. Efficacy of aliskiren/ hydrochlorothiazide single-pill combinations in aliskiren non-responders. Blood Press. 2008;17 Suppl 2:31-40.

33. Drummond W, Munger MA, Rafique EM, Maboudian M, Khan M, Keefe DL. Antihypertensive efficacy of the oral direct renin inhibitor aliskiren as add-on therapy in patients not responding to amlodipine monotherapy. J Clin Hypertens (Greenwich). 2007;9:742-750.

34. Feldman RD, Zou GY, Vandervoort MK, Wong CJ, Nelson SA, Feagan BG. A simplified approach to the treatment of uncomplicated hypertension: a cluster randomized, controlled trial. Hypertension. 2009;53:646-653.

35. Verdecchia P, Angeli F, Mazzotta G, Gentile G, Reboldi G. The renin angiotensin system in the development of cardiovascular disease: role of aliskiren in risk reduction. Vasc Health Risk Manag. 2008;4: 971-981.
Integrated Blood Pressure Control

\section{Publish your work in this journal}

Integrated Blood Pressure Control is an international, peer-reviewed open-access journal focusing on the integrated approach to managing hypertension and risk reduction. Treating the patient and comorbidities together with diet and lifestyle modification and optimizing healthcare resources through a multidisciplinary team approach constitute key

\section{Dovepress}

features of the journal. This journal is indexed on American Chemical Society's Chemical Abstracts Service (CAS). The manuscript management system is completely online and includes a very quick and fair peerreview system, which is all easy to use. Visit http://www.dovepress.com/ testimonials.php to read real quotes from published authors 